\title{
Survey and Study on Rural Home-based Aged-care Mode Based on SWOT Analysis
}

\author{
Yan Gao \\ Yantai Nanshan University \\ Yantai, Shandong, China 265713
}

\author{
Shengqun Wang \\ Yantai Nanshan University \\ Yantai, Shandong, China 265713
}

\author{
Dapeng Cong \\ Yantai Nanshan University \\ Yantai, Shandong, China 265713
}

\begin{abstract}
As the family miniaturization trend become increasingly obvious in our country, empty nest family start to appear in rural areas showing a rising trend. Home-based agedcare mode is thought to be in line with the objective requirement of aging of population through positive investigation and SWOT analysis, which also can integrate the sources of family and society, is an inexorable trend of aged-care development in china and an economic suitable pension mode for empty nest elders in rural areas. At last, it probes into the practice approaches of home-based aged-care for empty nest elders in rural areas from the aspects of family, community and government.
\end{abstract}

Keywords -rural empty nest elders; Aged-care mode; Homebased aged-care; SWOT analysis

\section{INTRODUCTION}

Rural community refers to the peasant-based community with economic activity of agriculture-based production mode ${ }^{[1]}$. It shows that the dependency ratio of rural population older than 65 is $13.73 \%$, of the city is $12.82 \%$ and of the town is $12.56 \%$ according to the data of 2009 sample survey on population change, meaning the aging population problem in rural is even more serious than urban as well as it has a higher proportion of disabled and half disabled elders [2], hence, the task of aged-care in rural is more arduous. From 1964 to 2010 in our country, the population elder than 65 and old-age dependency ratio are on the rise and the radio had been up to $11.9 \%$ in 2010; moreover, it will grow persistently in the coming decades [3]. In addition, the increasing amount of aged population and the process of aging of population in the world indicate that the characteristic of aging advanced population appears more obviously upon aging of population reaches a certain degree [4]. Meanwhile the home-based aged-care service has been developed in each big city, together with the various source advantages, giving a bigger chance to help the disabled elders in urban, on the other hand, traditional rural family provide single and weak support for aged-care[5].

The survey data of this research are from China Statistical Yearbook, Society Statistical Yearbook of China, China Demographic Yearbook edited by State Statistics Bureau and field investigation.

\section{SuRVEy on AgED-CARE Status OF RURAL EMPTY NEST ELDERS}

This survey, with respect to life statuses of empty nest elders living in part rural areas of coastal cities in Shandong province, mainly adopts the concentrated investigation manner, assisted by individual household survey and specifically takes method of combining questionnaire survey, case survey and collective interview. In consideration of the respondents' specificity that advanced age and poor education, the questionnaire mainly adopts preparer mode assisted by depth interview. This survey has handed out 150 questionnaires in total and retrieved 139 ones, of which there are 124 valid questionnaires, the valid return rate is $82.6 \%$, showing the comparatively high return rate and effectiveness. The questionnaire mainly covers the following questions: basic information, economic, daily care, spiritual and cultural life as well as the desire and demands for old-age support etc. Then we can analyze the aged-care current situations of rural empty nest elders from three aspects of economic support, daily care and spiritual consolation.

\section{A. Economic Support Aspect}

In the economic support aspect, many rural empty nest elders are still living on agricultural production by themselves. In addition, in most rural areas, the parents still bear the cost of their children's tuition, job application, marriage and house purchase etc. For the less affluent parents which are far too a white elephant.

The investigative statistics shows that the rural empty nest elders with income below RMB 200 per month account for $46.2 \%$ of the 150 investigated ones, which has lower income. The elders who are enjoying or have enjoyed social support have a relatively low percentage, only $8.9 \%$ of the empty nest elders have pensions and retirement pay and still $46.6 \%$ of empty nest elders never enjoy any support from the society. Result in that economic support problem, which is confronted with the rural empty nest elders, turns to be the first aged-care problem. 


\section{B. Daily Care Aspect}

Lack of carefulness is a common phenomenon in rural empty nest family. Some specialists point that under the family care, the daily interaction and support between children and parents have an obvious effect on the elders' physical and mental health [6]. From the interview, we can know that although most investigated rural empty nest elders can take care of themselves, there are still disabled and half-disabled elders exist. When asked about the question what they worry most, the less-cared rural empty nest elders express significant worry about their health problem, particularly their life in case of disabled. Being unattended has become the most perplexed problem in their later life.

\section{Spiritual Consolation Aspect}

The rural empty nest elders bear a great psychological gap, in case that their spouse are alive then the rural empty nest old couples can support each other in spirit, once widowed, it will bring a huge spiritual wound to the empty nest elders, even worst result in physical diseases and mental problems. From the investigation questionnaires, we can see that $64 \%$ of empty nest elders choose watching TV, newspaper or listening to radio as their entertainment lifestyle, most of them have a single spiritual and cultural life without any other recreative ways. The spiritual and cultural life of the rural empty nest elders are also fairly inadequate, particularly the mental life statuses of female empty nest elders are worth more attentions.

\section{SWOT ANALYSIS ON SECURITY SYSTEM OF RURAL HOME-BASED AGED-CARE}

This article conducts comparative analysis on the data derived from the questionnaires through SWOT.

\section{A. Analysis on the Strength of Rural Old-age Security}

1) There are abundant rural labor resources supporting the rural home-based aged-care mode: All the aged-care contents of economic support, daily care and spiritual consolation for rural elders can be borne by their families and the government could spend fewer funds on building concentrated nursing institutions for the aged, making the elders live in the acquainted committee and environment and providing facilities and services for the aged.

2) It is in line with Chinese traditional thought: Rural home-based aged-care, which carries on the traditional Chinese ideas, can take a good care of the elders without leaving their own family. Not only they can still live in the acquainted environment and can keep emotional relations with surrounding relatives and neighbors, but also facilitate their children to take care of elders and make them feel relived with the security of health and safety to the elders provided by the committee. Moreover, they can be filial at the elders' residence when they go back home to visit their parents.

3) The low costs of aged-care are in line with the economic bearing capacity of most elders in rural: The costs of rural home-based aged-care are far much less relative to organization support. The organization support needs to bear the cost of accommodation, medical service and other aspects, high expenses of which make the rural elders step back. However, by the means of home-based aged-care, the rural elders do not have to bear the costs of rent, water and electric created by living in nursing home. Meanwhile, they can take full advantages of the life resources at home.

\section{B. Analysis on the Weaknesses of Rural Old-age Security}

1) Commercial pension insurance cannot resolve the whole problem of peasant supporting universally: At present, the types of insurance in rural launched by various commercial insurance companies are low guarantee extent, high premium rate and single type, to some degree, it is less affordable to cover insurance in rural than cover in urban.

2) Upon China adopts the policy of reform and openingup, the coverage areas of collective aged-care in rural are limited: Most of these areas can only maintain the elders' basic survival, due to the abolition of the agricultural tax and village public accumulation funds-collection. Due to there are some unreasonable usage of the funds, the people who originally want to invest the home-based aged-care service work, are not willing to donate their money to committee directly.

\section{Analysis on the Opportunities of Rural Old-age Security}

The current rural economic development level in our country determines that social elder security cannot replace the family supporting roundly, with the family supporting weaken gradually, hence it is required that a newly aged-care mode aligned with the rural society development in our country. The opinion on comprehensively promote the service work of home-based aged-care points that the home-based aged-care service refers to a service mode provided by government and social force rely on the committee, including daily care, housekeeping service, hygiene care, spiritual consolation, entertainment and other aspects.

The elders live in their own home according to their own willingness with economic support mainly provided by families (including children, spouse and person), the rural empty nest elders of which are entitled to the services of daily care, medical care and spiritual consolation provided by committee and society with national policy support and institutional guarantee. Hence, the home-based aged-care is also a socialization of family supporting. Due to the social practice of low economic development level in most parts of current rural areas and being on the elders' desires, giving prominence to the organic combination of family supporting and committee supporting, laying stress on developing clustered synergy, it is deemed that the concept of the rural committee home-based aged-care could be more normative and comprehensive.

\section{Analysis on the Threats of Rural Old-age Security}

With the development of economic and the urbanization movement of the population, the family supporting function weakens gradually in our country and the traditional family supporting confronts a serious challenge; collective aged-care 
mode, which originally exist lots of institutional defaults, mainly depends on the collective economic strength; social supporting is limited by the economic development level with a narrow coverage and low security level, meanwhile exists various problems in operation; self-support by aged also have to face the indeterminacy of income, hardly can eliminate the various kinds of accident risk occurred in the daily life of rural empty nest elders. Along with the acceleration of urbanization, the problem of support elders turns to dominant from recessive, hence, explore and build a proper supporting mode suitable for rural empty nest elders is extremely urgent.

\section{Strategic SELECTION BASED ON SWOT ANALYSIS}

\section{A. Increasing Financial Support of the Government}

The government must guide home-based aged-care service as social and welfare services. The rural areas originally have worse economic conditions and even less participation power with market, provided that no subsidy policy and incentive measures from the government, it will lose the appeal to the qualified enterprises and other related organizations. Even though they join the elderly services, due to the low benefits, it may have harmful effects on the quality and quantity of the provided services and normal supply of the home-based agedcare services [8]. The main responsibilities of the government required by the ideas of modern service government are to provide welfares and services for members of the society, guaranteeing that people's basic living needs can be meet.

\section{B. Completing Social Security System in Rural Areas}

First, the government shall provide necessary social supporting through completing the rural minimum living guarantee system and Five Guaranteed system as well as realize the effective connection of assistance system and subsidies in services, avoiding wasteful duplication of efforts and assistance deficiency phenomenon occurred at the same time. Moreover, the government should set national uniform personal underwriting accounts for peasant-workers, strive to expand the coverage of social security and promote the level of overall planning, so as to make the insurance period can interflow, mutual recognition and continuation. The guiding opinion of the State Council also point that new rural endowment insurance realize the full coverage to rural people before 2020, which establishes a good economic base and policy background for carrying out rural aged-care services.

\section{Actively Developing Self-raised Funds}

The rural areas can use the village collective resources to raise the funds and materials for carrying out rural aged-care services as well. In addition, it should properly develop some elders' economic. Home-based aged-care service is a significant social and welfare service for elders; hence, it is required to maintain its low-cost and welfare.

\section{Competing the System of Service Team Construction}

The service staff can be classified into full-time and parttime stuff in nature and in terms of the different skills required by the service contents, the full-time staff can be divided into administrative staff, specific nurse, and fulltime care service staff. It should continue to carry out the policy of "three supports and one assistance", encourage the college graduates of medical specialty to work in village and community clinics.

\section{E. Mature Service Management System}

Scientific supervision and management system is an important guarantee for carrying out home-based aged-care service. In the process of service work of rural committee home-based aged-care, the guidance and specification of the government is fairly necessary. Only with reasonable overall planning, complete supervision evaluation mechanism and clarify the responsibilities of related departments, can maintain the service system running orderly.

\section{CONCLUSION}

In conclusion, home-based aged-care mode, which complies with the object requirements of aging of population, is suitable for the realistic national conditions and traditional culture customs. In addition, it can also satisfy the elders' willingness of living home and be beneficial to the integration of the committee resources and family resources, which will reduce the costs of social supporting. Moreover, it can remedy the weaknesses of home-based aged-care mode by the means of committee services. Hence, home-based aged-care mode is an irresistible trend of the development of aged-care mode in our country, also is the rational choice for resolving the agedcare problem of rural empty nest elders under the current economic conditions in our country.

\section{REFERENCES}

[1] Zheng Hangsheng. New Introduction to Sociology [M]. China Renmin University Press. 2003.

[2] 2010 Statistical Yearbook of Population and Employment in China.

[3] Data sources: 2011 China Statistical Yearbook tidy.

[4] Zhang Yunwei. Status and Countermeasure on Home-based Aged-care Service in Shanghai City [D]. Shanghai Jiaotong University, 2005.

[5] The Report of Situation Research on Disability Elders in Rural and Urban of China, The Report of 2010 Research on Current Issues of Nationwide Disability Elders Carried Out by National Committee on Aging and China Research Center on Aging.

[6] Spritze, G. \& Logan, J.R (1992), Helping as Component of Parent-child Relations[J]. Journal of Gerontology, 29.

[7] Ren Xiaona. The Problem and Countermeasure Existed in Committee Home-based Aged-care Service [J]. Legal System and Society, 2009.11.

[8] Liu Xinping. Research on Construction and Development of Multicooperation System of Home-based Aged-care Service in Urban. [J]. The Journal of Gansu Institute of Administration. 2009.4.

[9] Gao Yan, Cong Dapeng. Research on the Problems and Explorations of Peasant-workers in the Process of Urbanization [J] Modern Agriculture, 2011,05 . 